\title{
AN CHARACTERIZATION OF JACKET-TYPE OFFSHORE STRUCTURE BY OP- ERATIONAL MODAL ANALYSIS
}

\author{
A. Ortigão ${ }^{1}$, C. J. Martins ${ }^{2}$ \\ ${ }^{1}$ Terratek Ltda, Rio de janeiro Brazil, http://www.terratek.com.br \\ ${ }^{2}$ Department of Civil Engineering, Federal Centre of Technological Education (correspond- \\ ing-cjmartins@civil.cefetmg.br)
}

\begin{abstract}
Identification of dynamic structural characteristics in engineering by means of their responses to measured vibration is an important step for the correct characterization and monitoring of real structures. This article presents the results of a dynamic load test performed on the PG oil platform, located at Talara, Peru. The work included measurements of vibration in twelve positions on the platform, located on the floors of the structure. As excitation source, it was mainly due to wind action and wave motion, and thus the measurements were made without interruption of the structure operation. The collected data were analyzed using non-parametric technique of digital signal processing, which provided the main dynamic parameters of the structure. From there, we proceeded to the elaboration of a numerical model of the structure, based on the Finite Element Method, which represents accurately its structural behavior.
\end{abstract}

Keywords: Operational modal analysis, Dynamic load test, Structural characterization, Structural vibration, Offshore structure.

\section{INTRODUCTION}

Identification of dynamic structural characteristics in civil engineering by means of their responses to measured vibration is an important step for their correct characterization and monitoring since the dynamic properties are intimately related to service performance of structural elements.

The procedures by which dynamic characteristics (natural frequencies, vibration and damping modes) of a structure are identified from vibration measurements on specific points considering the structure described by modal models and called Experimental Modal Analysis (Maia[1] et al 1998). This technique was initially developed in the sphere of mechanical engineering considering tests carried out that have known applications. Mechanical structures are generally small when compared to buildings, so applied loads, generally known by means of measurement of vibrations cased by jackhammers or by using a system of vibrators, make 
up an appropriate procedure for vibrating the vibration modes that apply to mechanical engineering structures (He and $\mathrm{Fu}[2], 2001)$.

On the other hand, due to the large size and dynamic characteristics of civil engineering structures, the application of loads to those structures can be inconvenient, such as: the need to completely or partially stop the use of the structure being tested; high cost since the shaking equipment can be large; risk of collapse of fragile structures. In addition, there is the possibility of shaking in less important modes. Thus starting in the 1990s there was a large advance in dynamic testing with vibration sources that correspond to the operational actions of the structure. These techniques, commonly called Environmental Modal Analysis (AMA) consider environmental actions (wind, waves, vehicles, pedestrians, equipment etc) as vibration sources and thus the problems described above related to tests with controlled forces for civil structures can be minimized (Crawford and Ward[3] 1964; Trifunac[4] 1972; Rodrigues[5] 2004).

In the modal identification methods based on the response of structural systems to environmental actions, vibration sources aren't measured experimentally and are unknown. It thus becomes necessary to assume specific hypotheses as far as their characteristics. These methods assume that vibration sources correspond to a type of white noise with a constant spectral density with a null measurement, and the various modes of vibration to be applied can be appropriately stimulated and identified (Giraldo[6] et al2009). In even more rigid structures in which the responses to environmental actions have very low amplitude, environmental modal analysis has been satisfactorily carried out. In fact, in recent years there has been a large development of measurement equipment that makes it possible to register movements with very small amplitudes.

Tests to measure the structure's response to environmental action involve obtaining large quantities of experimental information that must be processed with appropriate analysis methods, requiring computer techniques to be developed with the capacity to carry out the processing. The progress that's taken place in developing these computer techniques is recognized. They have the permitted development and practical application of methods to identify modal parameters from environmental action tests that were nearly impossible just a few years ago (Rodrigues[5], 2004).

Model identification techniques can be classified in two main groups: non-parametric (frequency domain) and parametric (time domain). Non-parametric methods are based on evaluating response functions of spectral density from the Fourier transformed temporal series determination (Brincker[7] et al 2001 and Rodrigues[5] 2004). Parametric methods involve choosing an appropriate mathematical model that simulates the dynamic behavior of the structure followed by identification of modal parameters in such a way that the model adjust in the best way possible to the experimental values. This method can be applied to correlation functions or directly to the response's temporal series.

When models based of correlation functions are considered, parametric techniques can be adopted that are widely applied to controlled and non-controlled load analyses with the techniques of Ibrahin (Ibrahim and Mikulcik[8], 1977), Minimal squared with complex exponentials (Brown[9] et al 1979) and Stochastic Identification of Subspaces (Peeters[10] 2000). Rodrigues[5] and Giraldo[6] et al provide greater detail of the technique in the time domain. 
This article presents the results of a dynamic load test performed on the PG oil platform, located in Talara, Peru. The work included measurements of vibration in twelve positions on the platform, located on the floors of the structure. As excitation source, it was mainly due to wind action and wave motion, and thus the measurements were made without interruption of the structure operation. The collected data were analyzed using non-parametric technique of digital signal processing, which provided the main dynamic parameters of the structure. From there, we proceeded to the elaboration of a numerical model of the structure, based on the Finite Element Method, which represents accurately its structural behavior.

\section{NUMERICAL MODEL}

\subsection{Overview}

The structure is composed predominantly of pipe, I and C structural ASTM-A53 grade steel elements and the deck with ASTM-A36 steel plates. The rig includes an upper and lower deck $6.4 \mathrm{~m}$ apart. At a distance $5.94 \mathrm{~m}$ below the lower deck there is another one called "headings or cabezales".

The jacket support structure has a total height of $16.8 \mathrm{~m}$ and includes four raked steel pipe columns (outside diameter $457 \mathrm{~mm}$ ) with $406 \mathrm{~mm}$ steel pipe bracings. The raked columns serve as template guides for the $406 \mathrm{~mm}$ diameter foundation piles. Figure 1 gives an overview of the structure.

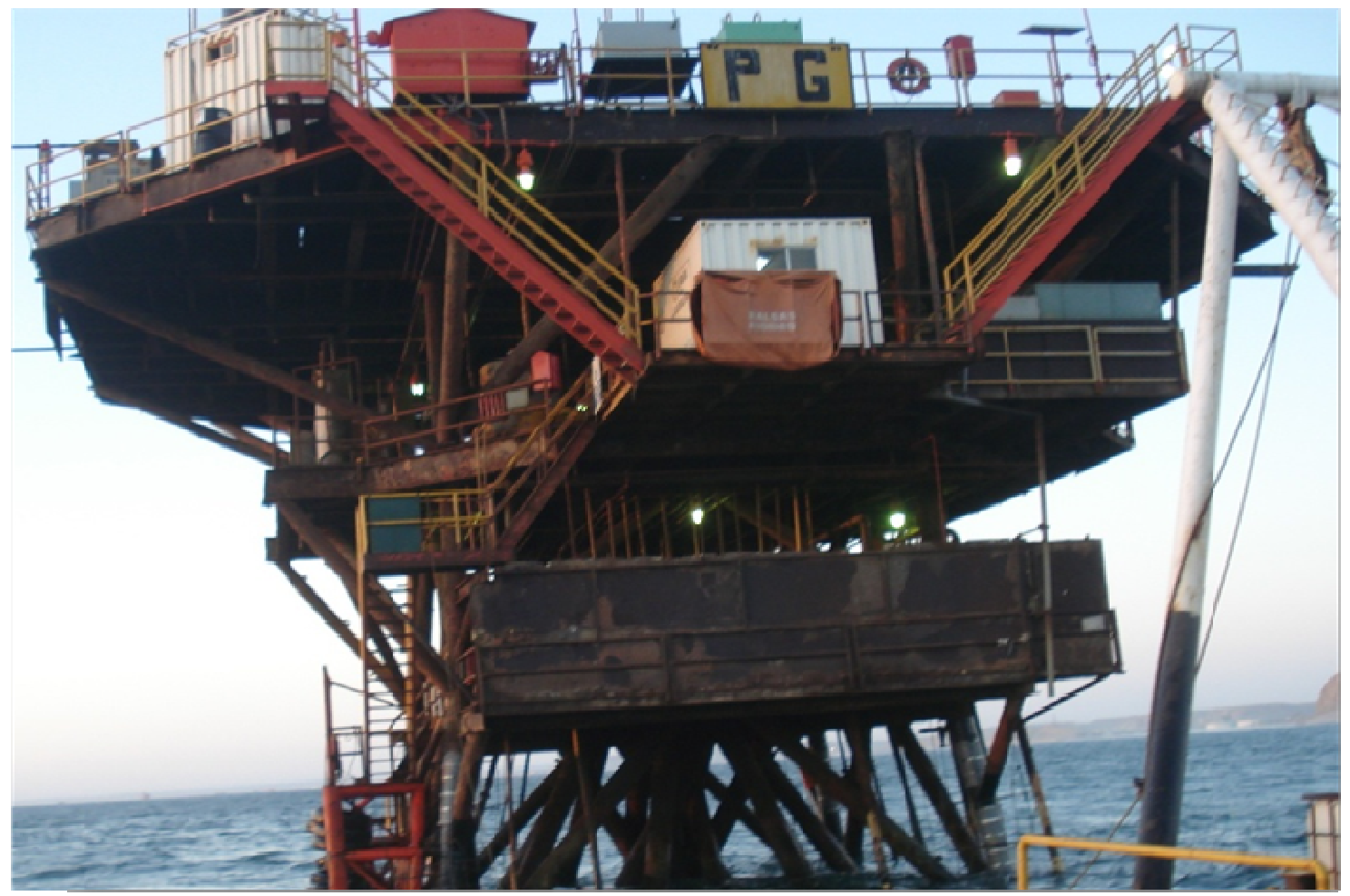

Figure 1. Platform PG - Talara/Peru". 


\subsection{Undamaged model}

The model geometry was based on the dimensions given by existing drawings and the visual inspection carried by structural specialist. Model includes 1434 bar elements and 736 plates with a total of 5610 degrees of freedom.

The model considers staircases and handrails as linear masses, since these elements do not have a significant contribution to stiffness. The equipment on the decks was modelled as lumped masses.

The deck floors were modelled with plate elements. The upper deck thickness was reduced to $6.3 \mathrm{~mm}$ to take into account corrosion. The lower deck was modelled as a $12 \mathrm{~cm}$ thick timber plate. The "headings or cabezales" was modelled as an orthotropic plate element with a $30 \mathrm{~kg} / \mathrm{m}^{2}$ mass. Figure 2 presents an overview of structural model.

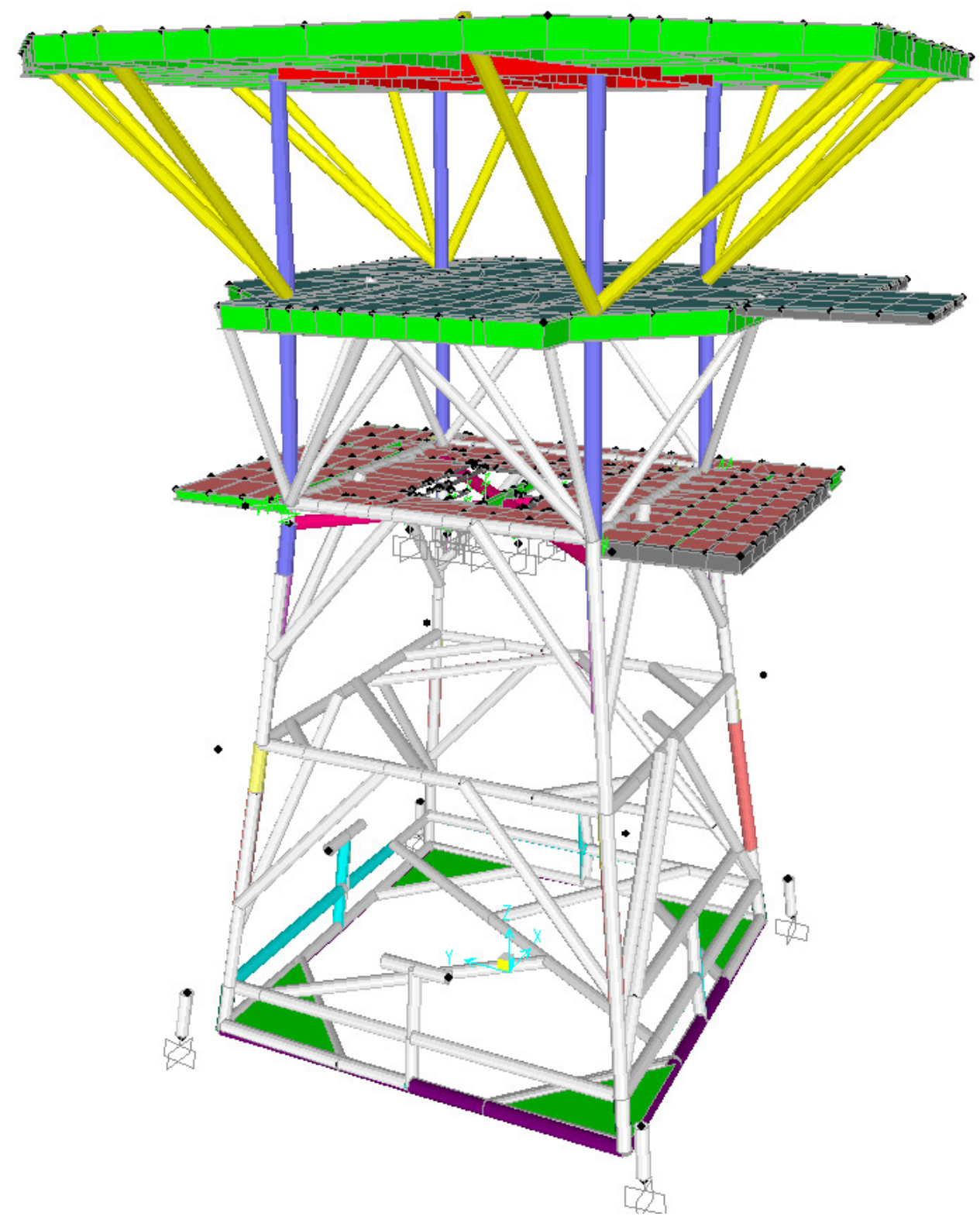


Figure 2. Initial model - 1434 bar and 736 thin shell elements.

\subsection{Measuring}

The measured vibrations were obtained under normal operational conditions of the oil rig. The source of excitation was solely waves, winds and mechanical equipment operating on the platform. The signal analysis technique known as SSI Stochastic Subspace Identification(Peeters[10] 2000). was then employed to extract the structural modes of vibration, consisting of order, frequencies and damping coefficients.

Figure 3 shows the measuring equipment and figure 4 the locations of data collection. Table 1 indicates the duration of each measure while table 2 indicates the direction of accelerometers.

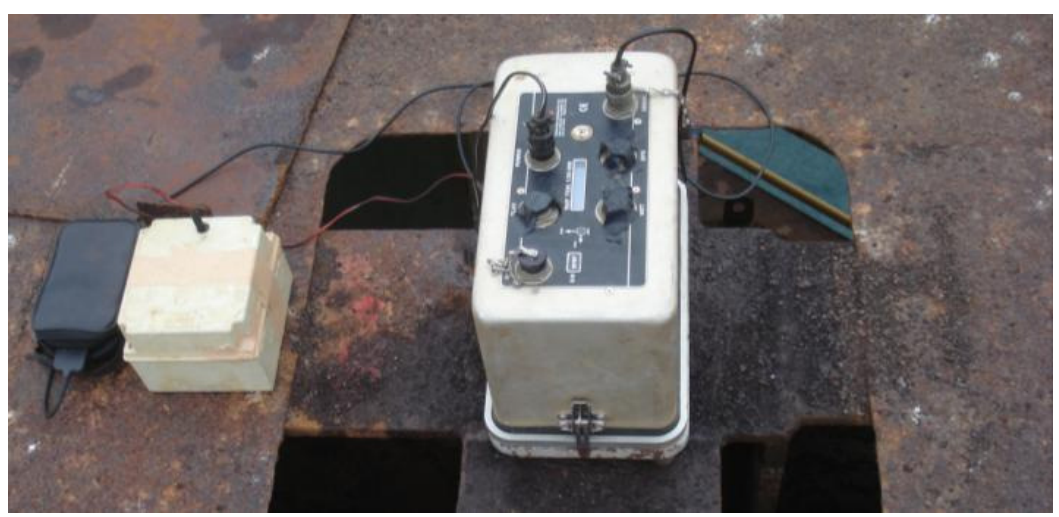

Figure 3- Equipment positioned on structure

Table 1: Time of measuring

\begin{tabular}{|c|c|c|}
\hline Point & Date & Duration \\
\hline P1 & $20 / 05 / 2011$ & 1h 30min \\
\hline P2 & $20 / 05 / 2011$ & 1h 30min \\
\hline P3 & $20 / 05 / 2011$ & 1h 32min \\
\hline P4 & $20 / 05 / 2011$ & 1h $15 \mathrm{~min}$ \\
\hline P5 & $21 / 05 / 2011$ & 1h 32min \\
\hline P6 & $21 / 05 / 2011$ & 1h 30min \\
\hline P7 & $21 / 05 / 2011$ & 1h 31min \\
\hline P8 & $21 / 05 / 2011$ & 3h 00min \\
\hline P9 & $21 / 05 / 2011$ & 1h 30min \\
\hline P10 & $22 / 05 / 2011$ & 1h 31min \\
\hline P11 & $22 / 05 / 2011$ & 1h 33min \\
\hline P12 & $22 / 05 / 2011$ & 1h 37min \\
\hline
\end{tabular}

Table 2: Convention for direction of accelerometers

\begin{tabular}{|c|c|}
\hline Accelerometers & Direction \\
\hline $\mathrm{Z}(1)$ & Vertical \\
\hline
\end{tabular}




\begin{tabular}{|c|c|}
\hline $\mathrm{Y}(2)$ & North direction \\
\hline $\mathrm{X}(3)$ & East direction \\
\hline
\end{tabular}

Figures 5 to 7 show the spectral density functions of the measured signals. These functions are suitable for spectral analysis of random signals. The figures show the amount of energy distributed over the frequency components, and provide subsidies for the determination of modal parameters.

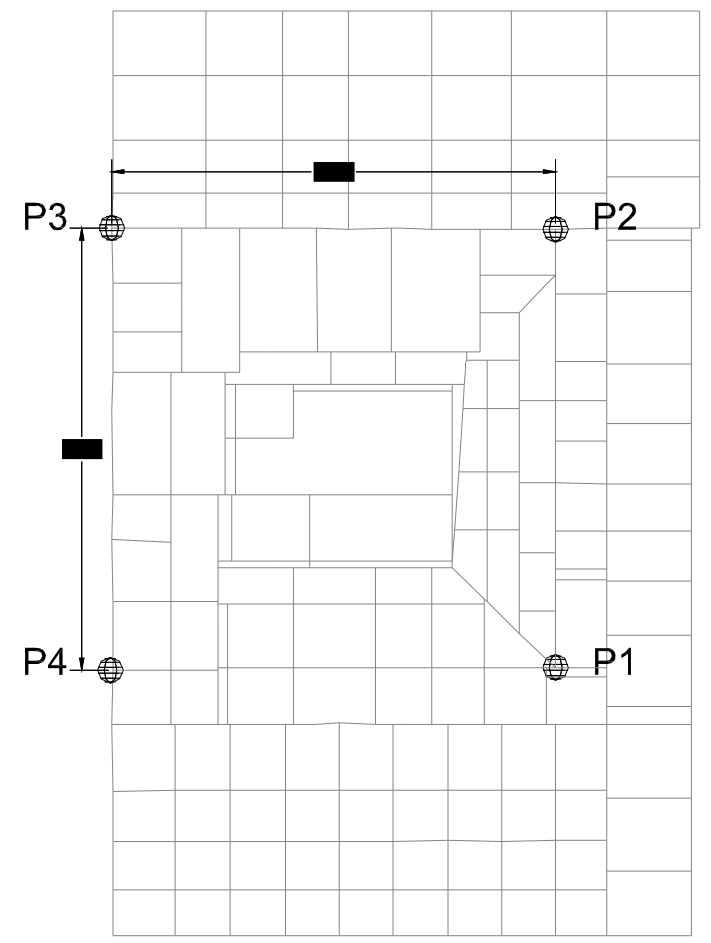

Cabezale's floor

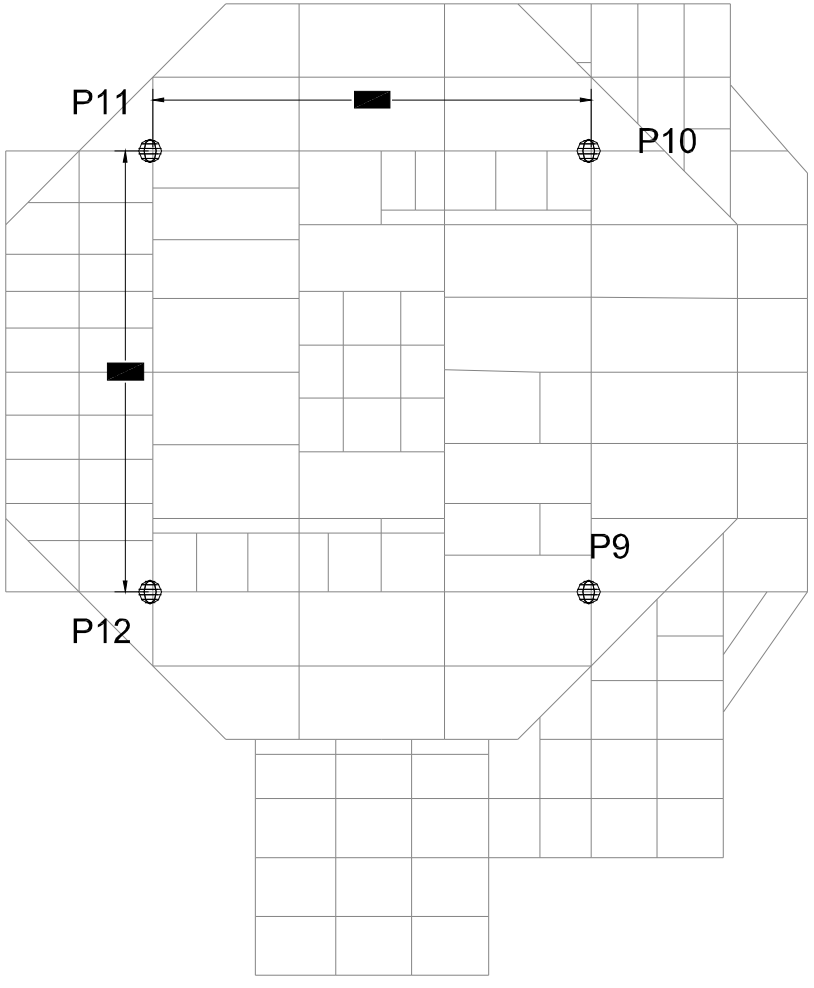

First floor 


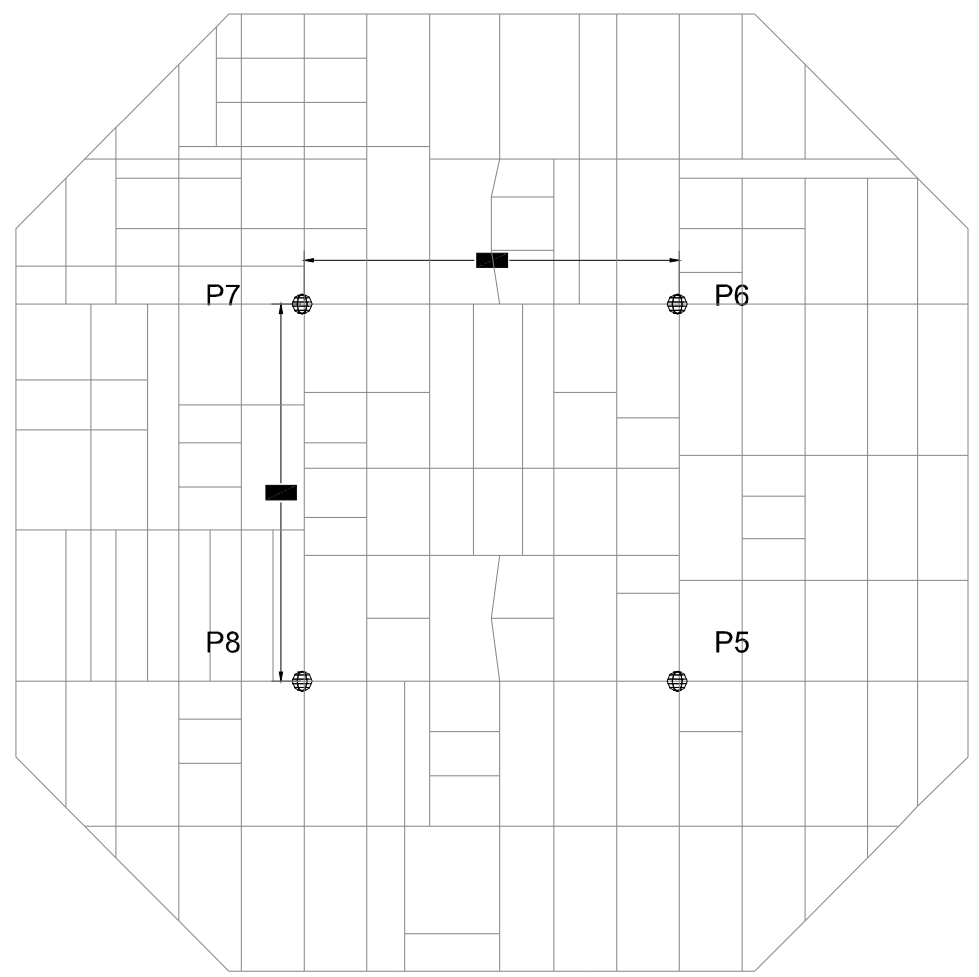

Second floor

Figure 4- Measurement locations on the structure decks 

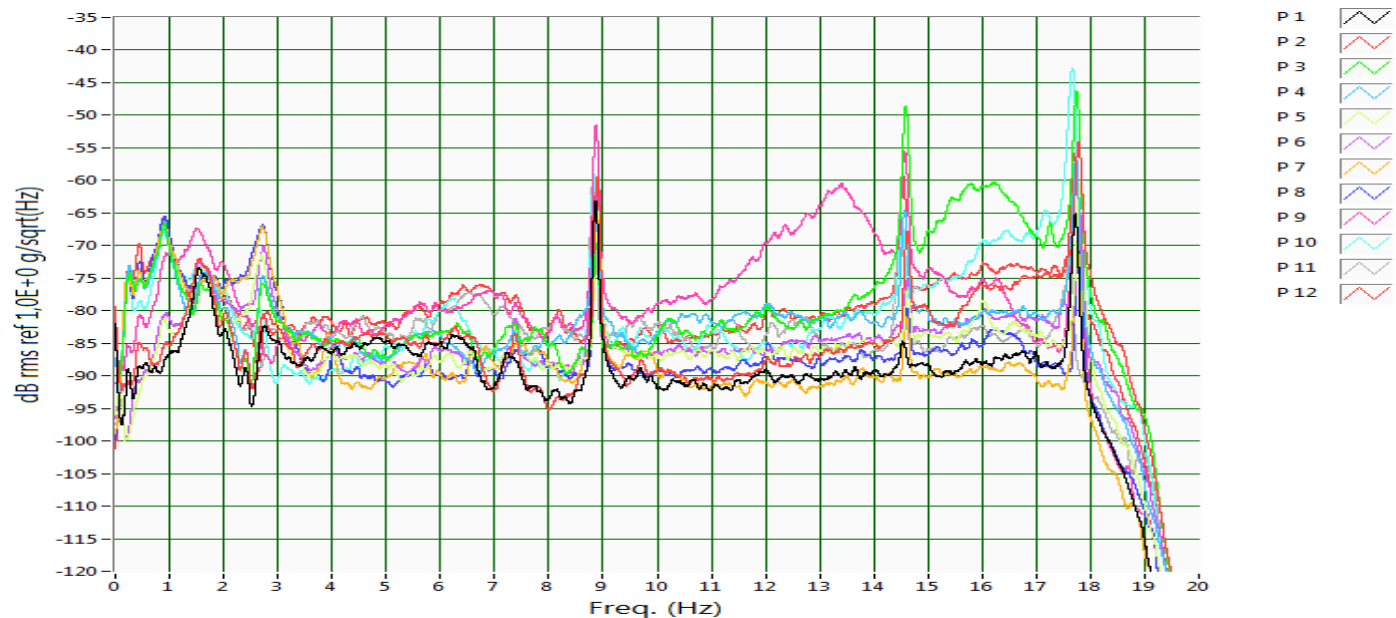

Figure 5 - Spectral density function - X(3) direction

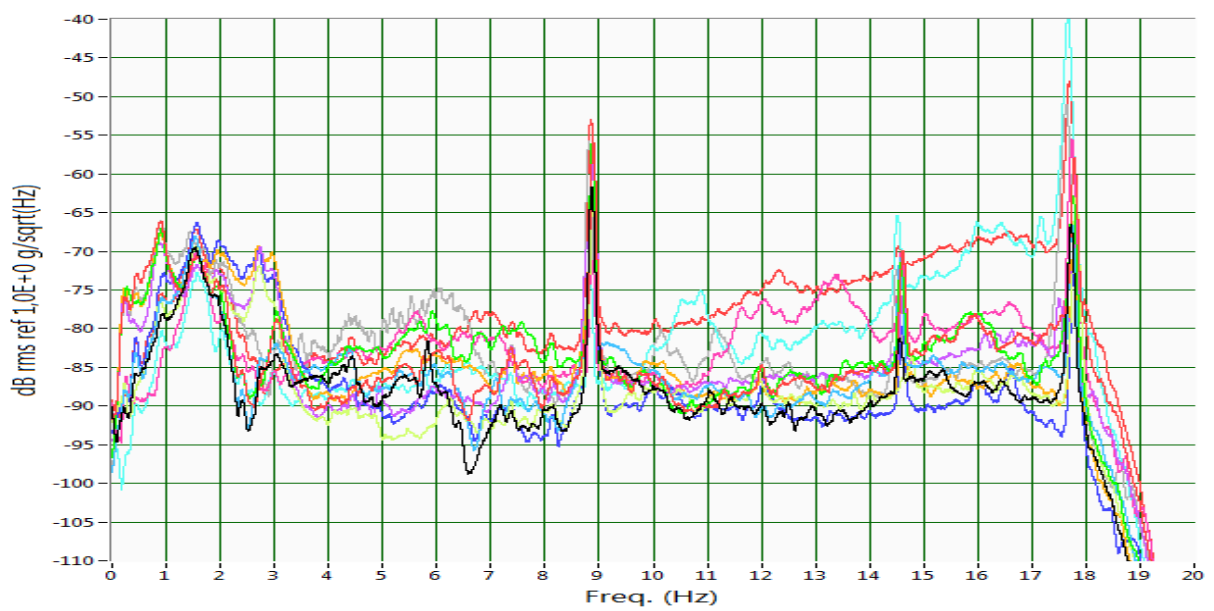

P1 $\leadsto$

$\mathrm{P}_{3}$

P 4

P5

P.

$\mathrm{P}_{8} \sim$

$3 2 \longdiv { W }$

10

11

Figure 6 - Spectral density function - Y(2) direction

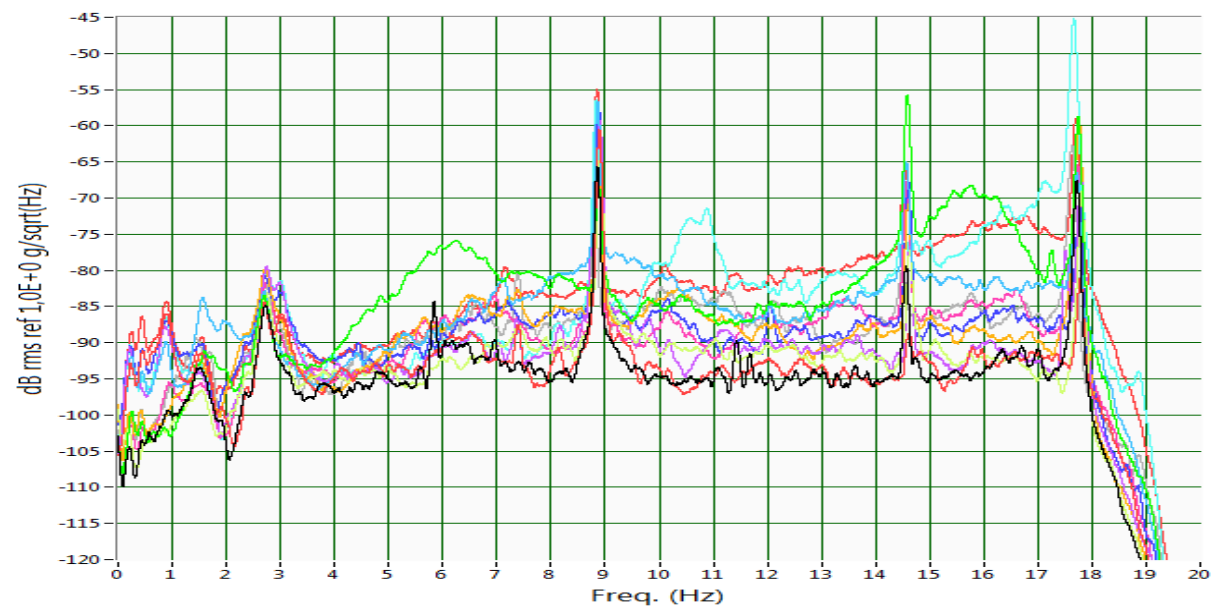

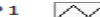

$\mathrm { P } 2 \longdiv { }$

3

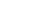

(1)

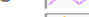

P\&

P 9

112

Figure 7 - Spectral density function - Z(1) direction 


\subsection{Modal frequencies identification}

This consisted of using the SSI algorithm to get rid of false modes or non structural modes, as well as local modes. Figure 8 presents the stabilization diagram, which is generated during the SSI algorithm. It enables separate of false from real modes. The real ones are those which remain, as at the top of the diagram with increasing order of the model. The false modes disappear, as the order increases. Table 3 presents the final results: the extracted modes and damping values

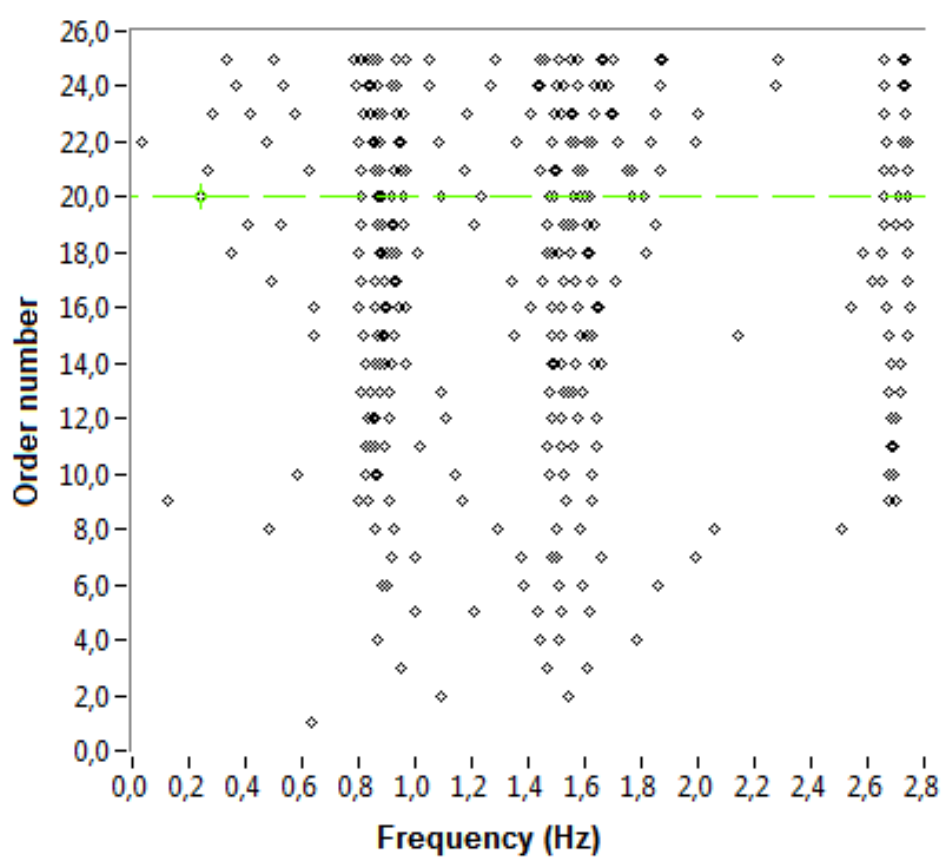

Figure 8. Acquired data in frequency domain.

Table 3: Extracted vibration modes by Stochastic Subspace Identification (SSI)

\begin{tabular}{|c|c|c|c|}
\hline Mode & $\begin{array}{c}\text { Frequencies (dam- } \\
\text { ped) }(\mathrm{Hz})\end{array}$ & $\begin{array}{c}\text { Frequencies (undam- } \\
\text { ped values) (Hz) }\end{array}$ \\
\hline 1 & 0.77 & 32.09 & 0.81 \\
\hline 2 & 0.84 & 7.34 & 0.85 \\
\hline 3 & 0.92 & 7.46 & 0.92 \\
\hline 4 & 1.02 & 28.98 & 1.07 \\
\hline 5 & 1.25 & 8.00 & 1.25 \\
\hline 6 & 1.47 & 2.45 & 1.47 \\
\hline 7 & 1.53 & 2.76 & 1.53 \\
\hline 8 & 1.82 & 8.52 & 1.83 \\
\hline 9 & 1.97 & 4.82 & 2.98 \\
\hline 10 & 2.65 & 2.05 & 2.64 \\
\hline 11 & 2.64 & 5.16 & 2.70 \\
\hline 12 & 2.70 & 6.42 & 2.86 \\
\hline 13 & 2.86 & 3.10 & 2.93 \\
\hline 14 & 2.93 & 2.27 & \\
\hline
\end{tabular}


This item describes the numerical calibration process which led to validation of the model. Figure 9 and table 4 give the dynamic characteristics of undamaged initial model and its eigenvalues. It was then modified step-by-step using a trial and error procedure in order to obtain an agreement with the measured resonances.

The damage introduced in the model consisted of reducing stiffness of selected elements and their joints until there was an agreement between modelled and measured eigenvalues. Figure 9, 10 and table 4 present the results for the validation of the initial 14 modes. Figure 11 and table 5 show that the calibrated modes are responsible for $90 \%$ of the mobilised mass. (EN 1998-1[15] 2003).

Figure 12 present the calibrated eigenvalues. Figure 13 present a percent stiffness reduction and element joints which rotation was allowed up to $20 \%$ ( $0 \%$ represents pinned free rotation and $100 \%$ fixed behaviour in 3D).

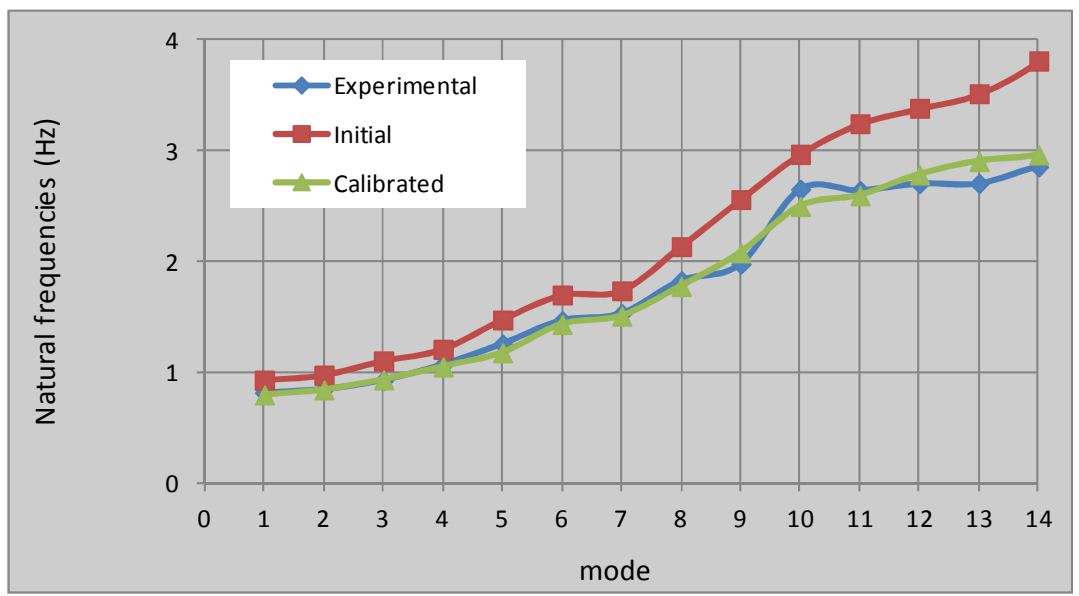

Figure 9 - Measured and calibrated frequencies

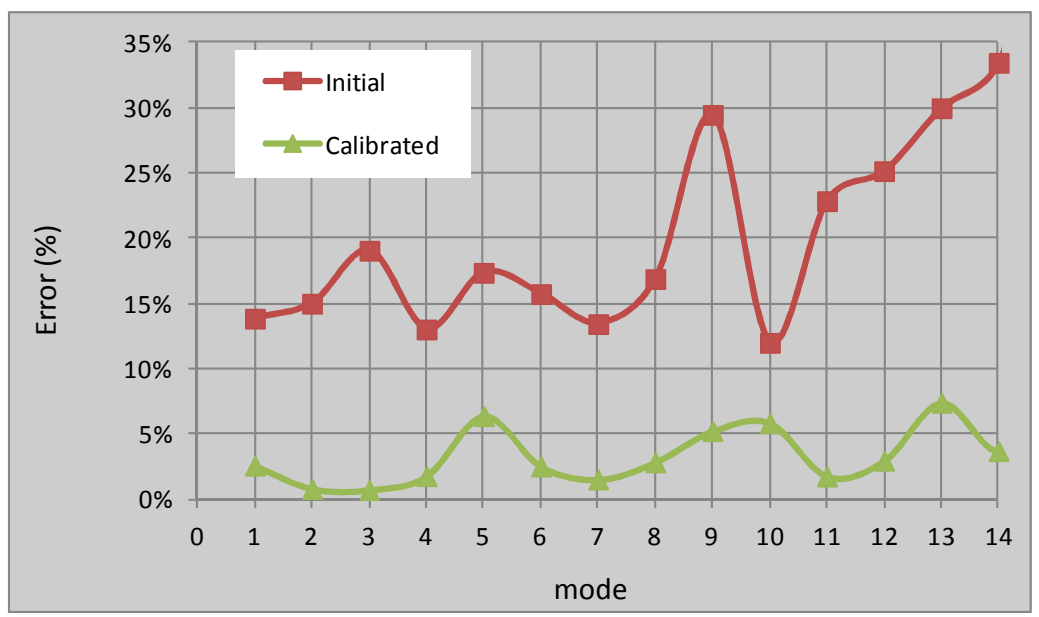

Figure 10 - Frequency error in the calibration process 
Table 4 - Measured and calibrated modes

\begin{tabular}{|c|c|c|c|c|c|}
\hline \multirow{2}{*}{ Mode } & Experimental & \multicolumn{2}{|c|}{ Initial model } & \multicolumn{2}{c|}{ Calibrated model } \\
\cline { 2 - 6 } & Freq. (Hz) & Freq .(Hz) & Error & Freq.(Hz) & Error \\
\hline 1 & 0.814 & 0.93 & $14 \%$ & 0.80 & $2 \%$ \\
\hline 2 & 0.845 & 0.97 & $15 \%$ & 0.84 & $0 \%$ \\
\hline 3 & 0.925 & 1.10 & $19 \%$ & 0.93 & $1 \%$ \\
\hline 4 & 1.067 & 1.21 & $13 \%$ & 1.05 & $2 \%$ \\
\hline 5 & 1.254 & 1.47 & $17 \%$ & 1.17 & $7 \%$ \\
\hline 6 & 1.466 & 1.70 & $16 \%$ & 1.43 & $3 \%$ \\
\hline 7 & 1.530 & 1.74 & $13 \%$ & 1.51 & $2 \%$ \\
\hline 8 & 1.827 & 2.14 & $17 \%$ & 1.78 & $3 \%$ \\
\hline 9 & 1.976 & 2.56 & $29 \%$ & 2.07 & $5 \%$ \\
\hline 10 & 2.652 & 2.97 & $12 \%$ & 2.50 & $6 \%$ \\
\hline 11 & 2.642 & 3.24 & $23 \%$ & 2.59 & $2 \%$ \\
\hline 12 & 2.705 & 3.38 & $25 \%$ & 2.78 & $3 \%$ \\
\hline 13 & 2.856 & 3.52 & $23 \%$ & 2.90 & $1 \%$ \\
\hline 14 & 2.929 & 3.81 & $30 \%$ & 2.96 & $1 \%$ \\
\hline
\end{tabular}

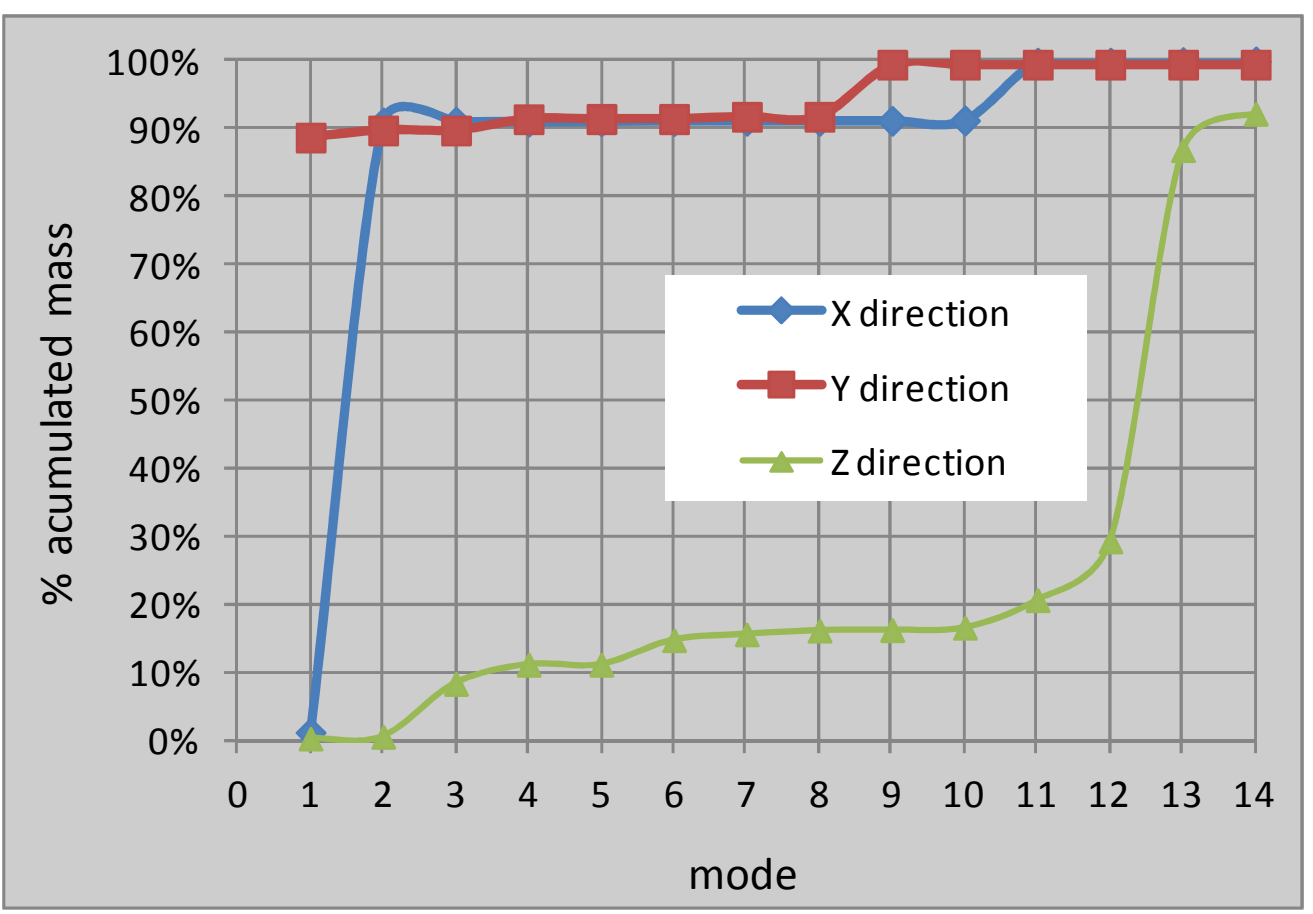

Figure 11 - Percentage of mobilized mass

\section{CONCLUSION}

In this work we present the procedures and results of modal analysis for a fixed offshore platform, considering like vibration source their natural actions. It was adopted only twelve measurement points, suitably positioned so that the principal modes of vibration of the struc- 
ture were obtained. The studies have used advanced techniques of digital signal processing, and thus the natural frequencies and structural damping could be obtained even for lowamplitude vibrations.

The experimental values of natural frequencies were used to calibrate a numerical model based on FEM. The main damages included in the calibrated model consisted in the reduction of the geometrical properties of cross sections and the introduction of partial releases of bonds between the bars. The consideration of such damage allowed the main natural frequencies of the numerical model to be fitted to the experimental values.

The calibrated model, considered a good numerical approximation of the structure may be used as a powerful tool to aid in the structural verification of the platform and to allow monitoring of its structural safety.

\section{Acknowledgements}

The authors acknowledge the financial support by CEFET/MG, CNPq, CAPES and FAPEMIG

\section{REFERENCES}

[1] N. Maia, J.M. Silva, J. He, N. Lieven, N. Lin, R. Lin, G. Skingle, W.M. To, A. Urgueira, "Theoretical and Experimental Modal Analysis", Research Studies Press, London, England. , 1998

[2] J. He, Z. Fu, "Modal analysis“, Butterworth-Heinemann, Oxford, England, 2001.

[3] J. Rodrigues, "Stochastic Modal Identification - Methods and Applications in Civil Engineering Structures“, Ph.D. Thesis, Univ. of Porto, Portugal, 2004.

[4] R. Crawford, H. S. Ward, "Determination of the Natural Period of Buildings“", Bulletin of the Seismological Society of America, Vol. 54, No. 6, pp. 1743-1756, 1964.

[5] M. D. Trifunac, "Comparison Between Ambient and Forced Vibration Experiments", Earthquake Engineering and Structural Dynamics, Vol. 1, pp. 133-150, 1972.

[6] D. F. Giraldo, W. Song, S. J. Dyke, J. M. Caicedo, "Modal Identification through Ambient Vibration: Comparative Study“, Journal of Engineering Mechanics, Vol. 135, No. 8, pp. 759-770, 2009.

[7] R. Brincker, C. Ventura, P. Andersen, P., "Damping Estimation by Frequency Domain Decomposition“, Proc. 19th Int. Modal Analysis Conference, San Antonio, USA, 2001.

[8] S. R. Ibrahim, E. C. Mikulcik, "A Method for the Direct Identification of Vibration Parameters from the Free Response“", The Shock and Vibration Bulletin, Vol. 47, No. 4, pp. 183-198, 1977.

[9] D. L. Brown, R. J. Allemang, R. Zimmerman, M. Mergeay, "Parameter Estimation Techniques for Modal Analysis“, SAE Technical Paper Series, No. 790221, 1979.

[10] B. Peeters, "System Identification and Damage Detection in Civil Engineering", Ph.D. Thesis, K. U. Leuven, Belgium, 2000.

[11] M. I. Ribeiro, "Análise de Sistemas Lineares“, IST Press, Portugal, 2002.

[12] O.C. Zienkiewicz, R.L. Taylor, 1989, "The Finite Element Method", Vol. 1-2, McGraw-Hill. 
[13] T.J.R. Hughes, “The Finite Element Method, Linear Static And Dynamic Finite Element Analysis“, 2 ed. New Jersey, Prentice-Hall, 2000.

[14] P. Andersen, "Identification of Civil Engineering Structures using Vector ARMA Models“, PhD Thesis, Department of Building Technology and Structural Engineering, University of Aalborg, Denmark, 1997.

[15] EN 1998-1, "Eurocode 8: Design of structures for earthquake resistance Part 1: General rules, seismic actions and rules for buildings“", 2003.

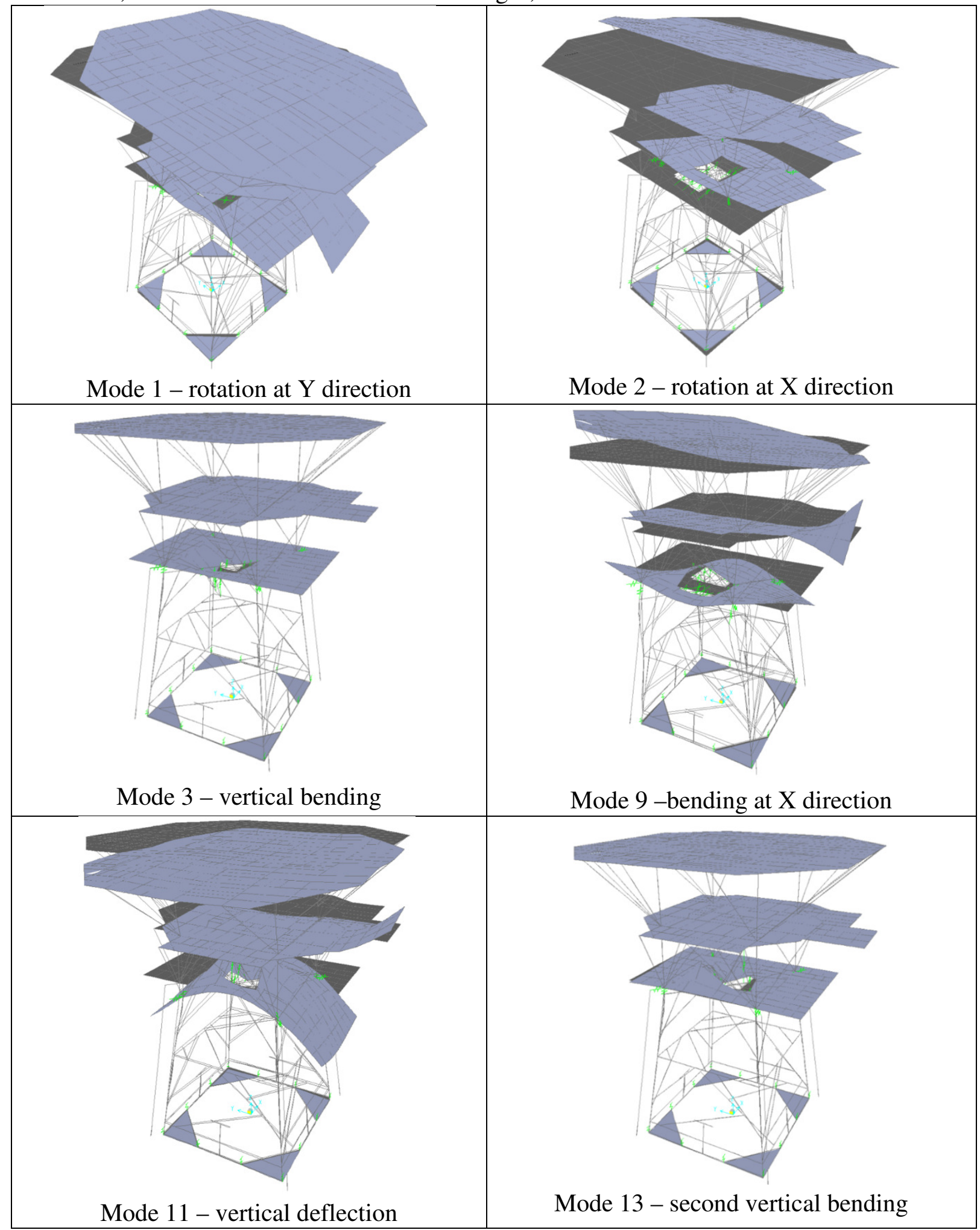

Figura 12 - Modes de vibração - modelo calibrado 


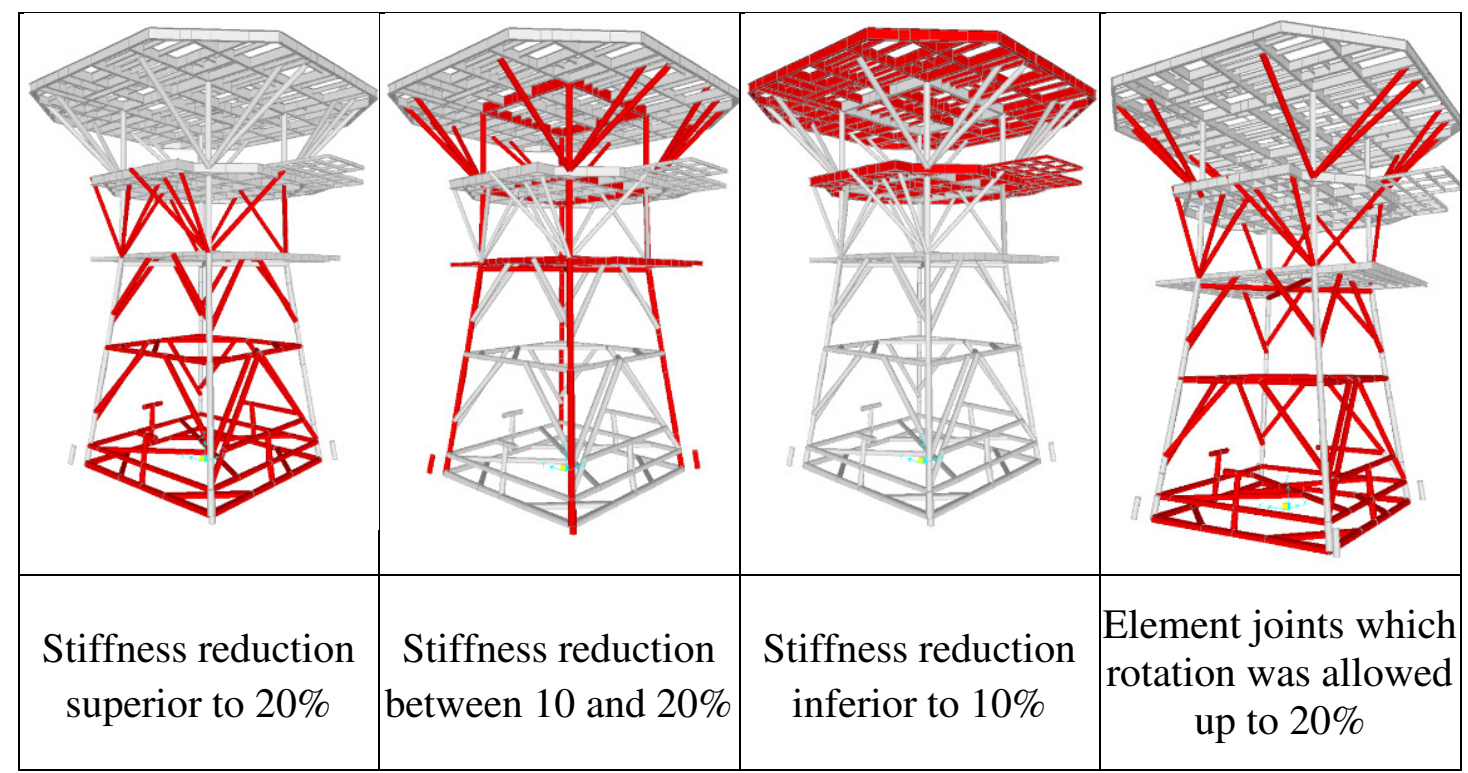

Figure 13 - Damage introduced on calibrated model 